\title{
Desempenho de vacas em lactação recebendo dietas com diferentes teores de amido total, acrescidas ou não de levedura (Saccharomyces cerevisiae) ${ }^{1}$
}

\author{
Flávio Augusto Portela Santos ${ }^{2}$, Carolina de Almeida Carmo ${ }^{3}$, Júnio Cesar Martinez ${ }^{3}$, \\ Alexandre Vaz Pires ${ }^{2}$, Carla Maris Machado Bittar ${ }^{2}$
}

\author{
${ }^{1}$ Projeto financiado pela FAPESP. \\ 2 Departamento de Zootecnia - ESALQ/USP - Piracicaba - SP \\ ${ }^{3}$ Pós-graduação em Ciência Animal e Pastagens - ESALQ/USP - Piracicaba - SP.
}

RESUMO - Trinta e seis vacas da raça Holandesa (258 dias em lactação) foram utilizadas para se avaliar a suplementação com levedura (Levucell SC 20 da Lallemand) em dietas para vacas leiteiras com dois teores de amido (22 vs 32\%). O mais baixo teor de amido foi obtido com a substituição parcial (50:50) de milho finamente moído por polpa de cítrus peletizada. Utilizou-se quadrado latino 4 × 4 repetido, com quatro períodos de 24 dias. Os primeiros 20 dias foram destinados à adaptação dos animais e os últimos quatro, à coleta de dados. Os parâmetros avaliados foram a ingestão de matéria seca, a produção e composição do leite e as concentrações de glicose e nitrogênio uréico no plasma sangüíneo. A ingestão de matéria seca, a produção e composição do leite e a concentração de glicose plasmática não foram afetadas pelos tratamentos. O nitrogênio uréico no leite foi maior nos animais sob suplementação com aditivo microbiológico. O nitrogênio uréico no plasma foi reduzido com a substituição parcial do milho pela polpa cítrica, que não teve efeito negativo sobre o desempenho de vacas produzindo, em média, $19 \mathrm{~kg}$ de leite/dia.

Palavras-chave: gado leiteiro, levedura, milho, polpa de citros, probiótico

\section{Supplementing yeast culture (Saccharomyces cerevisiae) for late lactating dairy cows fed diets varying in starch content}

\begin{abstract}
Thirty-six lactating Holstein cows averaging 258 days in milk were used to study the supplementation of yeast culture (Levucell SC20 - Lallemand) in dairy diets with two starch contents (22 vs. 32\%). The lowest starch content was obtained by partial (50:50) replacement of finely ground corn by dried citrus pulp. A replicated 4 x 4 Latin square design was used with four periods of 24 days each. The first 20 days were used for diet adaptation and the last four for data collection. The following variables were evaluated: dry matter intake, milk yield and composition, and plasma glucose and urea nitrogen. Yields of milk, fat corrected milk, protein, lactose, and total solids as well as concentration of plasma glucose were not affected by treatments. Milk fat content tended to increase by feeding yeast culture and high starch diets while milk fat yield tended to be highest only when yeast culture was fed together with the high starch diet. Partially replacing corn with dried citrus pulp reduced both milk urea nitrogen and plasma urea nitrogen in the present trial.
\end{abstract}

Key Words: dairy cattle, yeast culture, dried citrus pulp, corn, probiotic

\section{Introdução}

Os grãos de cereais, como milho e sorgo, são algumas das principais fontes de energia em dietas para vacas leiteiras. Entretanto, em decorrência do elevado preço do milho, nos últimos anos tem crescido o interesse por fontes energéticas alternativas. O estado de São Paulo é o maior produtor de cítrus e, conseqüentemente, de polpa cítrica peletizada do Brasil, com produção anual estimada de 1.150.000 toneladas (Santos et al., 2004). Esta alta disponibilidade tem tornado este subproduto uma fonte energética concentrada mais competitiva que o milho.
Dietas contendo silagem de milho como volumoso e milho grão como principal fonte energética são normalmente ricas em amido total, com valores de 26 a 33\% na matéria seca. Teores elevados de amido na dieta podem predispor um $\mathrm{pH}$ ruminal crítico para a degradação de fibra no rúmen e para o teor de gordura do leite.

Trabalhos conduzidos recentemente (Santos et al., 2001; Nussio et al., 2002) sugerem que os níveis de amido total e amido degradável no rúmen - propostos como adequados por Theurer et al. (1999), em revisão de trabalhos realizados com dietas contendo alfafa como principal fonte de forragem - podem ser excessivos quando o volumoso é 
composto principalmente por silagem de milho. Nestes casos, a substituição parcial do milho por subprodutos não amiláceos, ricos em pectina e fibra digestível, como a polpa cítrica, pode ser uma alternativa viável para se reduzir o teor de amido da dieta, melhorar o ambiente ruminal e manter ou melhorar a produção e composição do leite, como observado por Santos et al. (2001) e Nussio et al. (2002).

O valor energético da polpa cítrica também é questionado, pois é inferior ao do milho, como descrito pelo NRC (2001). Os dados obtidos em estudos com silagem de milho (Santos et al., 2001; Nussio et al., 2002) e com pastagem tropical manejada intensivamente durante o verão (Martinez, 2004) sugerem que, quando a polpa substitui parcialmente o milho na dieta, seu valor energético torna-se igual ou superior ao do milho.

O interesse pelo uso de microrganismos fornecidos diretamente como suplementos alimentares para vacas leiteiras tem aumentado significativamente nos últimos anos. Um desses suplementos é a levedura Saccharomyces cerevisiae, apontada como provável responsável pela melhoria no desempenho animal, por proporcionar estabilização do pH ruminal, maior digestão de frações fibrosas da dieta, maior consumo e aumento na síntese microbiana. Arambel \& Kent (1990) sugerem que vacas sob estresse térmico recebendo dietas ricas em amido respondem melhor a este tipo de aditivo.

Experimentos in vitro também têm comprovado que, em alguns casos, a cultura de Saccharomyces cerevisiae altera favoravelmente a fermentação de misturas de microrganismos ruminais e estimula a síntese de lactato e a digestão de celulose por culturas puras de bactérias predominantemente ruminais (Nisbet \& Martin, 1991; Martin \& Nisbet, 1992; Callaway \& Martin, 1997). Embora os efeitos não sejam consistentes, vários modelos têm proposto efeitos estimulatórios da cultura de levedura sobre a fermentação ruminal (Wallace, 1994). Não se sabe como e porque as culturas de leveduras aumentam o número de bactérias, mas a causa provável é que a atividade respiratória das leveduras protege as bactérias anaeróbias do rúmen contra danos causados pelo oxigênio (Newbold et al., 1996).

Os trabalhos sobre desempenho, entretanto, têm apresentado resultados variáveis quanto ao uso de levedura para vacas leiteiras. Aumentos na ingestão de MS (Williams et al., 1991; Wohlt et al., 1998), na produção de leite (Williams et al., 1991; Piva et al., 1993; Adams et al., 1995; Putman et al., 1997; Kung et al., 1997; Robinson \& Garret, 1999; Wohlt et al., 1998; Chaucheyras-Durand et al., 1998) e na composição do leite (Piva et al., 1993) têm sido observados em vacas leiteiras alimentadas com levedura. Todavia, em outros estudos nos quais se utilizou a levedura, não foram encontradas diferenças na ingestão de MS (Piva et al., 1993; Robinson \& Garret, 1999) e na produção (Swartz et al., 1994) e composição do leite (Robinson \& Garret, 1999; Swartz et al., 1994).

Entre os diversos fatores que afetam a resposta de vacas leiteiras à suplementação com levedura, destacam-se o estádio de lactação, o tipo de forragem fornecida, a estratégia de alimentação e a proporção volumoso:concentrado da dieta (Piva et al., 1993).

Este estudo foi realizado com o objetivo de avaliar o desempenho de vacas em lactação alimentadas com dietas contendo diferentes teores de amido total, mediante a substituição parcial do milho por polpa cítrica peletizada, acrescida ou não de levedura (Saccharomyces cerevisiae).

\section{Material e Métodos}

O experimento foi conduzido nas instalações do Departamento de Zootecnia da Escola Superior de Agricultura “Luiz de Queiroz", Universidade de São Paulo, em Piracicaba - SP, que constaram de um sistema de confinamento do tipo free-stall com quatro lotes. Foram utilizadas 36 vacas da raça Holandesa aos 300 dias de lactação, produzindo, em média, $18 \mathrm{~kg}$ de leite/dia no meio do período experimental.

Os tratamentos consistiram da inclusão de levedura (LEVUCELL ${ }^{\circledR}$ SC20 da LALLEMAND), na quantidade $0,5 \mathrm{~g} / \mathrm{animal} / \mathrm{dia}$, em dietas contendo dois teores de amido total (22 e 32\%). Todas as dietas continham silagem de milho como volumoso e os teores de amido variaram com a substituição de até $50 \%$ do milho moído fino por polpa cítrica peletizada. As dietas, isoprotéicas, foram formuladas utilizando-se o programa NRC (2001) (Tabelas 1 e 2).

O período experimental teve duração de 96 dias, divididos em quatro períodos de 24 dias, sendo os 20 primeiros destinados à adaptação dos animais às dietas e os outros quatro, à coleta de dados.

Os animais foram pesados no meio e ao final do experimento e sua condição corporal foi avaliada no início e ao final de cada período, utilizando-se escala de 1 a 5 , como proposto por Wildman et al. (1982).

Os animais foram ordenhados duas vezes ao dia, às $6 \mathrm{e}$ $18 \mathrm{~h}$, e as produções de leite individuais entre os dias $21 \mathrm{e}$ 24 de cada período foram registradas utilizando-se medidores do tipo "Mark V". Amostras do leite de cada vaca foram coletadas também do $21^{\circ}$ ao $24^{\circ}$ dia de cada período e analisadas quanto aos teores de gordura, proteína, lactose, sólidos totais e uréia, realizando-se ainda a contagem de 
Tabela 1 - Composição das dietas experimentais (\% MS) Table 1 - Ingredient composition of the experimental diets (DM \%)

\begin{tabular}{lcccc}
\hline & \multicolumn{4}{c}{$\begin{array}{c}\% \text { da MS } \\
\text { N DM }\end{array}$} \\
\cline { 2 - 5 } & A22 & A22L & A32 & A32L \\
\hline $\begin{array}{l}\text { Silagem de milho } \\
\text { Corn silage }\end{array}$ & 49,6 & 49,6 & 49,6 & 49,6 \\
$\begin{array}{l}\text { Milho moído fino } \\
\text { Finely ground corn }\end{array}$ & 12,3 & 12,3 & 25,3 & 25,3 \\
$\begin{array}{l}\text { Polpa cítrica } \\
\text { Citrus pulp }\end{array}$ & 12,3 & 12,3 & 0,0 & 0,0 \\
$\begin{array}{l}\text { Farelo de soja } \\
\text { Soybean meal }\end{array}$ & 22,3 & 22,3 & 21,6 & 21,6 \\
$\begin{array}{l}\text { Supl. min. vit. } \\
\text { Min. vit. suppl. }\end{array}$ & 2,8 & 2,8 & 2,8 & 2,8 \\
$\begin{array}{l}\text { Bicarbonato de Na } \\
\text { Sodium bicarbonate }\end{array}$ & 0,7 & 0,7 & 0,7 & 0,7 \\
\hline
\end{tabular}

$\mathrm{A} 22$ = amido $22 \%$ sem levedura; $\mathrm{A} 22 \mathrm{~L}=$ amido $22 \%$ com levedura; $\mathrm{A} 32$ = amido $32 \%$ sem levedura, $\mathrm{A} 32 \mathrm{~L}=$ amido $32 \%$ com levedura . $A 22=22 \%$ starch without yeast $; A 22 L=22 \%$ starch with yeast $; A 32=32 \%$ starch without yeast; $A 32 L=32 \%$ starch with yeast.

Tabela 2 - Composição das dietas experimentais (\% MS)

Table 2 - Chemical composition of the experimental diets (\% DM)

\begin{tabular}{|c|c|c|c|c|}
\hline & \multicolumn{4}{|c|}{$\begin{array}{l}\% \mathrm{MS} \\
\% D M\end{array}$} \\
\hline & A 22 & A $22 \mathrm{~L}$ & A 32 & A $32 \mathrm{~L}$ \\
\hline MS (\%) & 44,0 & 44,0 & 43,9 & 43,9 \\
\hline $\begin{array}{l}D M(\%) \\
\text { MO (\% MS) }\end{array}$ & 96,7 & 96,7 & 97,5 & 97,5 \\
\hline $\begin{array}{l}O M(D M \%) \\
\text { PB (\% MS) }\end{array}$ & 18,4 & 18,4 & 18,4 & 18,4 \\
\hline $\begin{array}{l}C P(D M \%) \\
\text { FDN(\% MS) }\end{array}$ & 30,8 & 30,8 & 28,6 & 28,6 \\
\hline $\begin{array}{l}N D F(D M \%) \\
\text { FDA (\% MS) } \\
A D F(D M \%)\end{array}$ & 16,8 & 16,8 & 14,7 & 14,7 \\
\hline $\begin{array}{l}\text { Amido (\% MS) } \\
\text { Starch (DM \%) }\end{array}$ & 24,8 & 24,8 & 35 & 35 \\
\hline
\end{tabular}

$\mathrm{A} 22$ = amido $22 \%$ sem levedura; $\mathrm{A} 22 \mathrm{~L}=$ amido $22 \%$ com levedura; A32 $=$ amido $32 \%$ sem levedura, $\mathrm{A} 32 \mathrm{~L}=$ amido $32 \%$ com levedura.

$A A 22=22 \%$ starch without yeast A22L $=22 \%$ starch with yeast $;$ A32 $=32 \%$ starch without yeast; $A 32 L=32 \%$ starch with yeast.

células somáticas pelo processo de infra-vermelho, no Laboratório da Clínica do Leite do Departamento de Zootecnia da ESALQ/USP.

Os animais foram alimentados duas vezes ao dia, às 6 e $18 \mathrm{~h}$, efetuando-se, diariamente, a pesagem e o descarte das sobras de alimento antes do fornecimento do período da tarde. O consumo do alimento oferecido foi medido diariamente, em grupo, durante os quatro dias de coleta de dados de cada período.

As amostras de silagem e dos outros alimentos, feitas diariamente e no início de cada período experimental, respectivamente, foram armazenadas a $-18^{\circ} \mathrm{C}$. Posteriormente, foram secas a $55^{\circ} \mathrm{C}$ e analisadas quanto aos teores de MS ( 3 horas a $\left.105^{\circ} \mathrm{C}\right), \mathrm{MO}\left(3\right.$ horas em mufla a $\left.600^{\circ} \mathrm{C}\right), \mathrm{FDN}$ e
FDA, de acordo com Van Soest et al. (1991), em digestor Ankom. Determinaram-se ainda os níveis de PB, por condução térmica no equipamento Leco FP 528 (Leco Corporation, St. Joseph MI), e amido, segundo método descrito por Poore et al. (1993). As análises foram realizadas no Laboratório de Bromatologia do Departamento de Zootecnia da ESALQ/USP.

As amostras de sangue foram coletadas em tubos com antiglicolíticos e anticoagulantes no último dia de cada período, 4 horas após alimentação, centrifugadas $(4.000 \mathrm{rpm}$ por 20 minutos), armazenadas a $-18^{\circ} \mathrm{C}$ e, posteriormente, analisadas quanto aos níveis de glicose (Kit Sigma Trinder 505 nm - Sigma Diagnostics, St. Louis, MO) e uréia (Kit Analisa - Analisa Indústria e Comércio Ltda).

Adotou-se o delineamento experimental de quadrados latinos $4 \times 4$ repetidos, em arranjo fatorial, composto por dois níveis de substituição do milho (0 e 50\%) e duas doses de aditivo microbiológico $(0$ e $0,5 \mathrm{~g} / \mathrm{an} / \mathrm{d})$. Foram utilizados 36 animais distribuídos em nove quadrados latinos.

Os dados de consumo foram analisados em um quadrado latino simples, no qual cada grupo de animais, de cada tratamento, foi considerado a unidade experimental, uma vez que o consumo de alimento foi medido em grupo e não individualmente.

Os dados foram analisados pelo PROC GLM (General Linear Models) do programa estatístico SAS (1991), utilizando-se o teste de comparação de médias dos quadrados mínimos, a 5\% de significância, considerando-se até $10 \%$ como tendência de significância para a probabilidade do teste F na análise de variância e no teste de comparação de médias.

\section{Resultados e Discussão}

No início e ao final do período experimental, os pesos vivos foram de 610 e $640 \mathrm{~kg}$ e os escores corporais, de 3,2 e 3,3, respectivamente. Na Tabela 3 são apresentados os dados de produção e composição do leite, ingestão de MS e parâmetros sangüíneos para os tratamentos com $22 \%$ de amido, sem (A22) e com levedura (A22L), e com 32\%, sem (A32) e com levedura (A32L).

O teor amido da dieta ( $22 \times 32 \%$ na MS) não afetou a ingestão de MS ( $P>0,05)$ de vacas no terço final de lactação, com produção em torno de $19 \mathrm{~kg}$ de leite/dia. Santos et al. (2001), Nussio et al. (2002) e Scoton et al. (2003) também não observaram efeito do teor de amido na dieta sobre o consumo de MS de vacas nos terços médio e final de lactação.

A substituição de parte do amido por polpa cítrica peletizada permite elevar o teor de fibra na dieta e manter 
adequada disponibilidade de carboidrato degradável no rúmen. A fração fibrosa da polpa cítrica apresenta elevada digestibilidade ruminal, pois, apesar do teor médio de FDA (aproximadamente 24\% na MS), a polpa tem baixo teor de lignina ( $1 \%$ na MS), de modo que a quase totalidade da fibra é digerida no rúmen do animal (Orskov, 1987) e, portanto, não é fator limitante ao consumo de matéria seca.

Além do alto teor de carboidratos solúveis e da parede celular altamente digestível, a polpa cítrica apresenta em sua composição $25 \%$ de pectina, um carboidrato estrutural quase totalmente (90-100\%) degradável no rúmen (Nocek \& Tamminga, 1991; Van Soest, 1994).

Chesson \& Monro (1982) encontraram taxas de degradação da pectina de 30 a $45 \%$ por hora e sua quase completa degradação entre 12 e 18 horas.

De acordo com Van Soest (1987), a substituição de produtos com alto teor de amido (milho, mandioca) por alimentos com alto teor de pectina promove efeito desejável em dietas para vacas em lactação, como resultado da menor queda do pH ruminal, em razão da fermentação acética em substituição à láctica e da capacidade de tamponamento ruminal da pectina. Esse efeito pode resultar em ambiente ruminal mais adequado à atividade microbiana e estimular a ingestão de matéria seca. Entretanto, neste experimento, o consumo de matéria seca não foi alterado pela redução do teor de amido da dieta com a inclusão de polpa cítrica.

Reinato et al. (2002) observaram que o pH ruminal foi superior nos tratamentos em que houve substituição parcial do milho pela polpa, o que difere dos resultados obtidos por Santos et al. (2001) e Nussio et al. (2002), que não encontraram efeito da substituição parcial do milho por polpa sobre o pH ruminal.

Neste estudo, a suplementação com leveduras não aumentou $(\mathrm{P}>0,05)$ o consumo de matéria seca de vacas

Tabela 3 - Ingestão de MS, produção e composição do leite e parâmetros sangüíneos para os diferentes tratamentos

Table 3 - DM intake, milk yield and composition, and blood metabolites for the different treatments

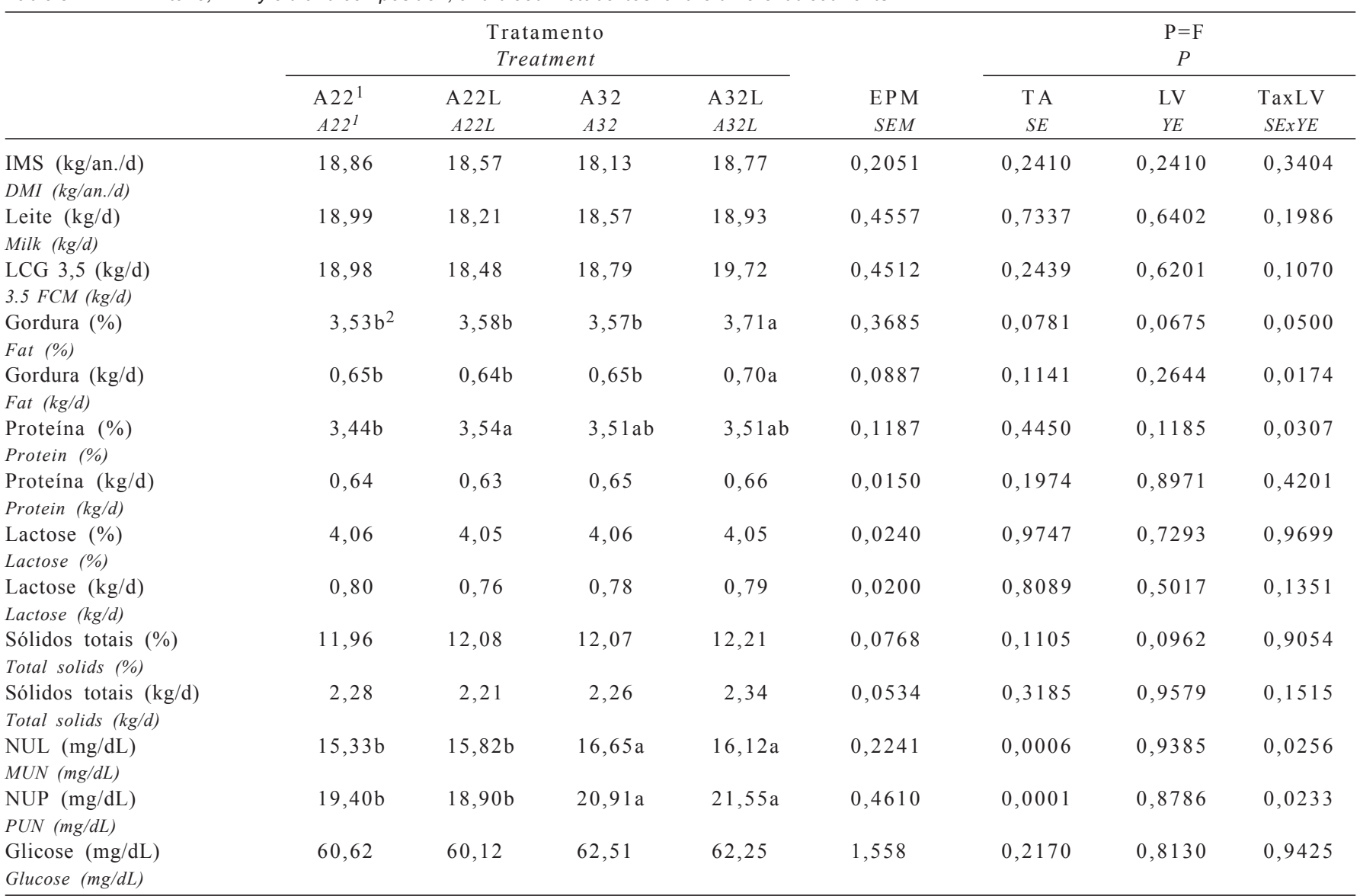

1 A22 = teor de amido $22 \%$, sem levedura; $\mathrm{A} 22 \mathrm{~L}=$ teor de amido $22 \%$, com levedura; $\mathrm{A} 32$ = teor de amido $32 \%$, sem levedura; $\mathrm{A} 32 \mathrm{~L}=$ teor de amido $32 \%$, com levedura; $E P M=$ erro-padrão da média; $P=F=$ probabilidade de haver efeito significativo entre os tratamentos; $T A=$ efeito do teor de amido; $L V=$ efeito da adição de levedura; TAxLV = interação teor de amido $\times$ adição de levedura; LCG 3,5 = leite corrigido para 3,5\% de gordura; IMS = ingestão de MS; NUL = nitrogênio uréico no leite; NUP = nitrogênio uréico no plasma

2 Médias na linha seguidas de letras distintas são significativamente diferentes pelo teste dos quadrados mínimos.

1 A22 = 22\% starch without yeast $; A 22 L=22 \%$ starch with yeast; $A 32=32 \%$ starch without yeast; $A 32 L=32 \%$ starch with yeast; SEM= standard error mean; $P=P$ value; SE= starch effect; $Y E=$ yeast effect; $S E X Y E=$ starch content $\times$ yeast interaction; $3.5 \% \mathrm{FCM}=3.5 \%$ fat corrected milk; DMI = DM intake; MUN= milk urea nitrogen; $P U N=$ plasma urea nitrogen.

2 Means in a row followed by different letters differ by least square test. 
no terço final de lactação, independentemente do teor de amido da dieta. Alguns dos possíveis benefícios do uso de microrganismos como suplemento alimentar seriam ambiente ruminal mais estável e maior digestão de matéria seca (Carro et al., 1992) e de fibra (Carro et al., 1992; Chaucheyras-Durand et al., 1998), favorecendo o consumo de MS.

Entretanto, os resultados de pesquisas sobre suplementação com leveduras para vacas em lactação têm sido muito variáveis. Alguns autores observaram aumentos na ingestão de matéria seca (Williams et al., 1991; Wohlt et al., 1998), enquanto outros não observaram efeito algum (Piva et al., 1993; Robinson et al., 1999).

Piva et al. (1993) sugeriram que vários fatores afetam a resposta de vacas leiteiras à suplementação com levedura, destacando o estádio de lactação, o tipo de forragem fornecida, a estratégia de alimentação e a proporção volumoso:concentrado da dieta. Em revisão sobre o assunto, Yoon \& Stern (1995) observaram aumentos significativos na ingestão de matéria seca em apenas 2 de 10 estudos.

Dann etal.(2000) avaliaram o efeito da suplementação com levedura em dietas para vacas Jersey, primíparas e multíparas dos últimos 21 dias pré-parto até os primeiros 140 dias pósparto sobre a ingestão de matéria seca e a produção e composição do leite. A suplementação com levedura aumentou a ingestão de matéria seca nos últimos sete dias de gestação e nos primeiros 42 dias de lactação. A suplementação também resultou em menor perda de peso corporal e menor utilização da reserva energética corporal para produção de leite das vacas durante o início da lactação. Embora as vacas sob suplementação tenham atingido o pico da lactação mais cedo, não houve aumento na produção total nem mudanças na composição do leite. Talvez a suplementação com levedura seja mais eficaz no período de transição e no início da lactação, quando o animal encontra-se em estresse mais intenso.

Arambel \& Kent (1990) sugeriram que a levedura pode ser melhor utilizada por animais sob estresse. Uma possível explicação para esse efeito é que baixa ingestão de matéria seca não proporciona à população bacteriana fatores de crescimento suficientes, como ácidos orgânicos, vitamina B e aminoácidos. Callaway \& Martin (1997) afirmaram que a cultura de levedura proporciona esses fatores estimulantes do crescimento de bactérias celulolíticas e da digestão de celulose.

As produções de leite e de leite corrigida para gordura não foram afetadas pelo teor de amido da dieta $(\mathrm{P}>0,05)$. A maioria dos trabalhos publicados não relata diferenças na produção de leite. Entretanto, tem-se observado significativo aumento nas produções de leite corrigidas para gordura com a inclusão de polpa cítrica peletizada na dieta (Van Horn et al., 1975; Lucci et al., 1975; Santos et al., 2001; Nussio et al., 2002); provavelmente, o aumento na produção e no teor de gordura do leite com o uso de polpa de cítrus peletizada seja resultado do aumento na digestibilidade das frações fibrosas da dieta, na proporção molar de acetato e da menor produção de ácidos graxos trans.

De acordo com o NRC (2001), a polpa cítrica tem valor energético inferior ao milho moído fino $(80,38$ x $88,68 \%$ de NDT) e, em qualquer simulação utilizando o programa do NRC (2001), a substituição parcial do milho por polpa resulta em menor produção de leite. A ausência deste efeito negativo da polpa em diversos estudos (Van Horn et al., 1975; Lucci et al., 1975; Santos et al., 2001; Nussio et al., 2002; Scoton et al., 2003) publicados na literatura pode ser explicada por alguns fatores: a) melhor ambiente ruminal, favorecendo a digestibilidade de nutrientes; b) maior digestibilidade ruminal dos carboidratos não-fibrosos da polpa cítrica em comparação aos do milho; c) a equação de Weiss, utilizada pelo NRC (2001), subestima o valor energético de subprodutos fibrosos ricos em pectina e açúcares.

A produção de leite não foi afetada pela suplementação com levedura $(\mathrm{P}>0,05)$. Apesar do interesse crescente pelo uso de probióticos para vacas leiteiras, os resultados de pesquisas com leveduras têm variado bastante. Aumentos na produção de leite em vacas leiteiras alimentadas com levedura têm sido observados por diversos pesquisadores (Williams et al., 1991; Piva et al., 1993; Adams et al., 1995; Putman et al., 1997; Kung et al., 1997; Robinson \& Garret, 1999; Wohlt et al., 1998; Chaucheyras-Durand et al., 1998), mas, em alguns trabalhos, não foram relatados resultados positivos (Arambel \& Kent, 1990; Dann et al., 2000; Soder $\&$ Holden, 1999; Swartz et al., 1994).

Em revisão sobre o assunto, Yoon \& Stern (1995) observaram aumentos significativos na produção de leite em apenas três de 11 estudos.

Diversos fatores podem afetar a resposta de vacas em lactação à suplementação com leveduras, destacando-se a qualidade do probiótico, a presença ou não de fatores causadores de estresse ou de desafio, o estádio de lactação e a produção de leite (Williams et al., 1991; Wohlt et al., 1998; Williams et al., 1991; Piva et al., 1993).

Ressalta-se que os resultados positivos, quando obtidos, são geralmente inferiores a $10 \%$ de aumento em leite. Para que respostas de 3 a $5 \%$ em produção de leite sejam detectadas estatisticamente, normalmente é necessário número considerável de vacas por tratamento, o que nem sempre é possível nas estações experimentais.

Houve interação significativa $(\mathrm{P}<0,05)$ teor de amido $\times$ suplementação com levedura para teor e produção de 
gordura do leite. O efeito benéfico da levedura ocorreu apenas nas dietas com alto teor de amido, corroborando a hipótese de que o ambiente ruminal é melhorado com o uso deste aditivo (Carro et al., 1992; Wallace, 1994; Newbold et al., 1996).

O efeito benéfico da levedura apenas nas dietas ricas em amido comprova que este tipo de aditivo tem maior chance de atuar de forma positiva quando as condições de ambiente ruminal são mais críticas. Entretanto, é difícil explicar o maior teor de gordura no leite de vacas alimentadas com dietas contendo maior teor de amido.

Uma das teorias mais aceitas atualmente sobre os mecanismo que afetam o teor de gordura do leite é a da produção e absorção de ácidos graxos de cadeia trans pelo trato digestivo da vaca leiteira e de seu efeito inibitório sobre a síntese de ácidos graxos de cadeia curta pela glândula mamária (NRC, 2001). A produção de ácidos graxos de cadeia trans no rúmen é intensificada em condições de pH desfavoráveis à biohidrogenação, realizada pelos microrganismos ruminais. Segundo Gaynor et al. (1994), esses ácidos graxos provocam diminuição na atividade da enzima carnitina acil transferase, que participa da formação de triglicerídeos no tecido da glândula mamária. A redução no teor de amido da dieta com a inclusão de polpa cítrica em substituição parcial ao milho pode resultar em ambiente ruminal mais favorável aos microrganismos ruminais (Van Soest, 1991) e, conseqüentemente, minimizar a produção de ácidos graxos de cadeia trans (NRC, 2001).

Segundo Oba \& Allen (2003), apesar de em diversos casos a média diária de $\mathrm{pH}$ ruminal não ser diferente, dietas com maior teor de amido resultam em maior variação diária do $\mathrm{pH}$ ruminal que aquelas com menor teor de amido. Esses autores propuseram que a partição dos nutrientes absorvidos para produção de leite ou reservas corporais é influenciada pela variação no $\mathrm{pH}$ ruminal, pois o $\mathrm{pH}$ ruminal determina o padrão de suprimento de combustíveis metabólicos do rúmen para a circulação sangüínea (Oba \& Allen, 2000). A taxa de absorção de ácidos pela parede do rúmen é afetada pelo pH ruminal, o qual, em menor flutuação diária, pode resultar em suprimento mais consistente de combustíveis metabólicos do rúmen para a circulação sangüínea, enquanto em maior flutuação, pode indicar o suprimento de energia mais variável. Esse suprimento variável de energia pode estimular a secreção de insulina, com aumento na utilização de energia no tecido adiposo maior que para a síntese de gordura do leite (Oba \& Allen, 2000).

A redução nos teores de gordura do leite observada por Oba \& Allen (2003), em dietas com mais amido, sem que houvesse maior fluxo de ácidos graxos trans para o intes- tino, reforça a tese dos autores acerca dos efeitos da flutuação do pH ruminal. Aparentemente, a síntese de gordura na glândula mamária é controlada por mais de um mecanismo.

Entretanto, os dados deste experimento divergem da maioria dos encontrados na literatura, observando-se aumento nos teores e nas produções de gordura do leite com a inclusão de polpa cítrica peletizada na dieta (Van Horn et al., 1975; Lucci et al., 1975; Santos et al., 2001; Nussio et al., 2002).

Alguns autores (Bargo et al., 2003; Martinez, 2004; Scoton et al., 2003), no entanto, não observaram efeito positivo no teor de gordura do leite ao reduzirem o teor de amido da dieta mediante a inclusão de polpa de cítrus.

Observa-se, a partir de alguns trabalhos, que a inclusão de polpa cítrica na dieta, sem substituição ao milho, aumenta o teor de gordura do leite, quando inferior a 3,5\% (Santos et al., 2001; Leiva et al., 2000). Pode-se supor que o efeito da inclusão da polpa cítrica seja pronunciado em situações em que os teores de gordura do leite são baixos.

Não houve efeito do nível de amido da dieta sobre o teor e a produção de proteína do leite ( $\mathrm{P}>0,05)$. Scoton et al. (2003) também não observaram efeito da inclusão de polpa cítrica sobre o teor e a produção de proteína do leite. Santos et al. (2001) constataram redução nos teores de proteína do leite com a substituição do milho por polpa cítrica. Entretanto, a combinação de fontes de amido de alta degradabilidade (milho floculado) com polpa cítrica manteve os teores de proteína do leite semelhantes aos obtidos com milho moído grosso.

Em três dos seis trabalhos revisados por Bargo et al. (2003), houve redução no teor de proteína do leite quando fontes de amido foram substituídas por subprodutos como a polpa cítrica no concentrado de vacas mantidas em pastagens temperadas. Martinez et al. (2003) não observaram efeito da substituição de milho por polpa sobre a produção e composição do leite de vacas mantidas em pastagens tropicais manejadas intensivamente.

A redução no teor de proteína do leite com a redução do teor de amido da dieta (Santos et al, 2001) poderia ser explicada pela menor síntese de proteína microbiana e pela mais baixa produção de propionato no rúmen, o que restringiria a disponibilidade de aminoácidos para a síntese de proteína na glândula mamária.

A suplementação com levedura aumentou o teor de proteína do leite apenas nas dietas com baixo teor de amido, observando-se interação significativa $(\mathrm{P}<0,05)$ teor de amido $\times$ suplementação com levedura. Vários autores não observaram efeito da suplementação com levedura sobre a proteína do leite (Piva et al., 1993; Swartz et al., 1994; Wohlt et al., 
1998; Robinson \& Garret, 1999; Soder \& Holden, 1999; Dann et al., 2000).

A suplementação com levedura não afetou os teores de NUP e NUL $(P>0,05)$. Entretanto, as concentrações de nitrogênio uréico no leite e no plasma foram menores $(\mathrm{P}<0,05)$ nos tratamentos com polpa cítrica. Santos et al. (2001) e Scoton et al. (2003) não observaram efeito da adição de polpa cítrica sobre a concentração de nitrogênio uréico no plasma.

O teor de nitrogênio uréico no leite se correlaciona com o teor plasmático, que, por sua vez, pode ser afetado pelo teor de nitrogênio amoniacal no fluido ruminal e pela proteína metabolizável com perfil inadequado de aminoácidos essenciais (NRC, 2001).

O uso de fontes de carboidratos de alta degradabilidade ruminal pode favorecer menor teor de nitrogênio uréico no leite, em razão da menor perda de $\mathrm{N}$-amonicacal pelo rúmen e do melhor perfil dos aminoácidos essenciais na proteína metabolizável, decorrente da maior participação da proteína microbiana (Theurer et al., 1999).

Uma hipótese para o efeito positivo da polpa em reduzir as concentrações de NUL e NUP seria sua alta disponibilidade de carboidratos rapidamente degradáveis no rúmen (açúcar e pectina), o que favoreceria a utilização do nitrogênio amoniacal pelos microrganismos ruminais.

Não houve diferença na concentração de glicose plasmática entre os diferentes tratamentos $(\mathrm{P}>0,05)$, como relatado por outros autores que avaliaram a inclusão de polpa cítrica na dieta (Lykos et al., 1997; Santos et al., 2001; Nussio et al., 2002).

\section{Conclusões}

Para vacas produzindo em torno de $19 \mathrm{~kg}$ de leite/dia, no terço final da lactação, a polpa cítrica apresentou valor energético igual ao do milho quando combinados na proporção 1:1.

Vacas no terço final de lactação, com produção de $19 \mathrm{~kg}$ de leite/dia, não responderam à suplementação com aditivo microbiológico.

\section{Literatura Citada}

ADAMS, A.L.; HARRIS, B.; VAN HORN, H.H. et al. Effects of varying forage types on milk production responses to whole cottonseed, tallow and yeast. Journal of Dairy Science, v.78, p.573-581, 1995.

ARAMBEL, M.J.; KENT, B.A. Effect of yeast culture on nutrient digestibility and milk yield response in early to midlactation dairy cows. Journal of Dairy Science, v.73, p. $1560-1563,1990$.
BARGO, F.; MULLER, L.D.; KOLVER, E.S. et al. Production and digestion of supplemented dairy cows on pasture. Journal of Dairy Science, v.86, n.1, p.1-42, 2003.

CALLAWAY, E.S.; MARTIN, S.A. Effects of Saccharomyces cerevisiae culture on ruminal bacteria that utilize lactate and digest cellulose. Journal of Dairy Science, v. 80, p.20352044, 1997.

CARRO, M.D.; LEBZIEN, P.; ROHR, K. Effects of yeast culture on rumen fermentation, digestibility ad duodenal flow in dairy cows fed a silage based diet. Livestock Production Science, v.32, p.219-229, 1992 .

CHAUCHEYRAS-DURAND, F.; FONTY, G.; BERTIN, G. Effet de Saccharomyces cerevisiae utilisée comme additif alimentaire sur les fonctions majeures de l'écosystème ruminai. In: CONGRÉS DE LA SOCIÉTÉ FRANÇAISE DE MICROBILOGIE, 5., 1998, Lille. Abstracts... Lille: 1998. p.147.

CHESSON, A.; MONRO, J. Legume pectic substances and their degradation in the ovine rumen. Journal of Science Food Agriculture, v.33, p.852, 1982.

DANN, H.M.; DRACKLEY, J.K.; McCOY, G.C. et al. Effects of yeast culture (Saccharomyces cerevisiae) on prepartum intake and postpartum intake and milk production of Jersey cows. Journal of Dairy Science, v.83, p.123-127, 2000.

GAYNOR, P.J.; ERDMAN, R.A.; TETER, B.B. et al. Milk fat yield and composition during abomasal infusion of cis or trans octadecenoates in Holstein cows. Journal of Dairy Science, v.77, p.157-165. 1994.

KUNG, L.; KRECK, E.M.; TUNG, R.S. Effects of a live yeast culture and enzymes on in vitro ruminal fermentation and milk production of dairy cows. Journal of Dairy Science, v. 80 , p.2045-2051. 1997.

LYKOS, T. et al. Varying degradation rates of total nonstructural carbohydrates: effects on ruminal fermentation, blood metabolites, and milk production and composition in high producing Holstein cows. Journal of Dairy Science, v. 80, n.12, p.3341-3355. 1997.

LUCCI, C.S.; VELloso, L.; MASOTTI, N. et al. Polpa seca de laranja versus milho desintegrado em misturas concentradas para vacas em lactação. Revista da Faculdade de Medicina Veterinária e Zootecnia da Universidade de São Paulo. v.12, p.163-168, 1975

MARTIN, S.A.; NISBET, D.J. Effect of direct-fed microbials on rumen microbial fermentation. Journal of Dairy Science, v.75, p.1736-1744, 1992.

MARTINEZ, J.C.; SANTOS, F.A.P.; VOLTOLINI, T.V. et al. Substituição parcial do milho moído fino por polpa cítrica peletizada no concentrado de vacas Holandesas em início de lactação, pastejando capim-elefante. 1. Produção e composição do leite, parâmetros sangüíneos, peso vivo e escore corporal. In: REUNIÃO ANUAL DA SOCIEDADE BRASILEIRA DE ZOOTECNIA, 40., 2003, Santa Maria. Anais... Santa Maria: Sociedade Brasileira de Zootecnia, 2003. (CD-ROM)

MARTINEZ, J.C. Substituição parcial do milho moído fino por polpa cítrica peletizada no concentrado de vacas leiteiras pastejando capim elefante durante outono inverno. Piracicaba: Escola Superior de Agricultura Luiz de Queiroz, 2004. 110p. Dissertação (Mestrado em Ciência Animal e Pastagens) - Escola Superior de Agricultura Luiz de Queiroz, 2004.

NATIONAL RESEARCH COUNCIL - NRC. Nutrient requeriments of dairy cattle. Washington, D.C.: National Academy Press, 2001. 381p.

NEWBOLD, C.J.; WALLACE, R.J.; McINTOSH, F.M. Mode of action of the yeast Saccharomyces cerevisiae as a feed aditive for ruminants. British Journal Nutrition, v.76, p.249-261, 1996.

NISBET, D.J.; MARTIN, S.A. Effect of a Saccharomyces cerevisiae culture on lactate utilization by the ruminal bacterium Selenomonas ruminantium. Journal of Animal Science, v.69, p.4628-4633, 1991. 
NOCEK, J.E.; TAMMINGA, S. Site of digestion of starch in the gastrointestinal tract of dairy cows and its effect on milk yield and composition. Journal of Dairy Science, v.74, p.35983629,1991 .

NUSSIO, C.M.B.; SANTOS, F.A.P.; PIRES. A.V. et al. Fontes de amido de diferentes degradabilidades e sua substituição por polpa de citrus em dietas para vacas leiteiras. Acta Scientarium, v.24, n.4, p.1079-1086, 2002.

OBA, M.; ALLEN, M.S. Effect of brown mibrid 3 mutation in corn silage on productivity of dairy cows fed two levels of dietary NDF: 1. Feeding behavior and nutrient utilization. Journal of Dairy Science, v.83, p.1333-1341, 2000 .

OBA, M.; ALLEN, M.S. Effects of corn grain conservation method on feeding behavior and productivity of lactating dairy cows at two dietary starch concentrations. Journal of Dairy Science, v.86, p. 174-183, 2003.

ORSKOV, E.R. The feeding of ruminants: principles and practice. Lincoln: Rowett Research Institute, Chalcombe Publications. 1987. $110 \mathrm{p}$.

PIVA, G.; BELLADONA, S.; FUSCONI, G. et al. Effects of yeast on dairy cow performance, ruminal fermentation, blood components, and milk manufacturing properties. Journal of Dairy Science, v.76, p.2717-2722, 1993.

POORE, M.H.; MOORE, J.A.; SWINGLE, R.S. et al. Effect of fiber source and ruminal starch degradability on site and extent of digestion in dairy cows. Journal of Dairy Science, v.76, p.2244, 1993 .

PUTMAN, D.E.; SCHWAB, C.G.; SOCHA, M.T. et al. Effect of yeast culture in the diets of early lactation dairy cows on ruminal fermentation and passage of nitrogen fractions and amino acids to the small intestine. Journal of Dairy Science, v.80, p.374384. 1997

REINATO, J.D.; EZEQUIEL, J.M.B.; GALATI. R.L. et al. Efeitos da substituição do milho pela polpa cítrica sobre o $\mathrm{pH}$ e nitrogênio amoniacal em dietas contendo dois níveis de subproduto da produção de lisina (SPL). In: REUNIÃO ANUAL DA SOCIEDADE BRASILEIRA DE ZOOTECNIA, 39., 2002, Recife. Anais... Recife: Sociedade Brasileira de Zootecnia, 2002. (CD-ROM)

ROBINSON, P.H.; GARRET, J.E. Effect of yeast culture (Saccharomyces cerevisiae) on adaptation of cows to postpartum diets and on lactational performance. Journal of Animal Science, v.77, p.988-999, 1999.

SANTOS, F.A.P.; MENEZES JR., M.P.; SIMAS, J.M.C. et al. Processamento do grão de milho e sua substituição parcial por polpa de citros peletizada sobre o desempenho, digestibilidade de nutrientes e parâmetros sangüíneos. Acta Scientarium, v.23, n. 4, p.923-931, 2001

SANTOS, F.A.P.; PEREIRA, E.M.; PEDROSO, A.M. Suplementação energética de bovinos de corte em confinamento. In: SIMPÓSIO SOBRE BOVINOCULTURA DE CORTE, 5., 2004, Piracicaba. Anais... Piracicaba: Fundação de Estudos Agrários Luiz de Queiroz, 2004.p.261-297.

STATISTICAL ANALYSIS SYSTEM - SAS. User's guide: statistics. 5.ed. Cary: 1991.
SCOTON, R.A.; SANTOS, F.A.P.; IMAIZUMI, H. et al. Substituição do milho moído fino por polpa cítrica peletizada e/ou raspa de mandioca na dieta de vacas leiteiras em final de lactação. In: REUNIÃO ANUAL DA SOCIEDADE BRASILEIRA DE ZOOTECNIA, 40., 2003, Santa Maria. Anais... Santa Maria: Sociedade Brasileira de Zootecnia, 2003. (CD-ROM)

SODER, K.J.; HOLDEN, L.A. Dry matter intake and milk yield and composition of cows fed yeast prepartum and postpartum. Journal of Dairy Science, v.82, p.605-610, 1999.

SWARTZ, D.L.; MULLER, L.D.; ROGERS, G.W. et al. Effect of yeast cultures on performance of lactating dairy cows: a field study. Journal of Dairy Science, v.77, p.3073-3080, 1994.

THEURER, C.B.; LOZANO, O.; ALIO, A. et al. Steam-processed corn and sorghum grain flaked at different densities alter ruminal, small intestinal, and total tract digestibility of starch by steers. Journal of Animal Science, v.77, p.2824-2831, 1999.

Van HORN, H.S.; MARSHALL, S.P.; WILCOX, C.J. et al. Complete rations for dairy cattle. III. Evaluation of protein percent and quality and citrus pulp - corn substitutions. Journal of Dairy Science, v.58, n.8, p.1101-1108. 1975.

Van SOEST, P.J. Soluble carbohydrates and the nonfiber components of feeds. Large Animal Veterinary, v.42, p.44, 1987.

Van SOEST, P.J. Nutrition ecology of the ruminants. Ithaca: Cornell University Press, 1994. 476p.

Van SOEST, P.J.; ROBERTSON, J.B.; LEWIS, B.A. Methods for dietary fiber, neutral detergent fiber, and nonstarch polysaccharides in relation to animal nutrition. Journal of Dairy Science, v.74, p.3583. 1991

WALLACE, R.J. Rumen microbiology, biotechnology, and ruminant nutrition: progress and problems. Journal of Animal Science, v.72, p.2992-3003. 1994

WICKES, R.B.; BARTSCH, B.D. Dried citrus pulp or barley as energy concentrates for dairy cows. Australian Society of Animal Production, v.12, p.180, 1978 (CAB Abstracts - CD-ROM).

WILDMAN, E.E.; JONES, G.M.; WAGNER, P.E. et al. A dairy condition scoring system and its relationship to selected production characteristics. Journal of Dairy Science, v. 65 , p.495, 1982

WILLIAMS, P.E.V.; TAIT, C.A.G., INNES, G.M. et al. Effects of the inclusion of yeast culture (Saccharomyces cerevisiae plus growth medium) in the diet of dairy cows on milk yield and forage degradation and fermentation patterns in the rumen of steers. Journal of Animal Science, v.69, p.3016-3026, 1991

WOHLT, J.E.; CORCIONE, T.T., ZAJAC, P.K. Effects of yeast on feed intake and performance of cows fed diets based on corn silage during early lactation. Journal of Dairy Science, v. 81, p.1345-1352, 1998.

YOON, I.K.; STERN, M.D. Influence of direct-fed microbilas on ruminal microbial fermentation and performance of ruminants: a review. Australian Asian Journal of Animal Science, v.79, p.411-417, 1995 